\title{
Social Interaction and Reflection for Behaviour Change
}

\author{
Bernd Ploderer ${ }^{1}$, Wolfgang Reitberger ${ }^{2}$, Harri Oinas-Kukkonen ${ }^{3}$, Julia van Gemert-Pijnen ${ }^{4}$ \\ ${ }^{1}$ Department of Computing and Information Systems, The University of Melbourne, \\ Australia \\ Email:ploderer@unimelb.edu.au \\ ${ }^{2}$ Institute for Design and Assessment of Technology, Vienna University of Technology, \\ Austria \\ Email:wolfgang.reitberger@tuwien.ac.at \\ ${ }^{3}$ Department of Information Processing Science, University of Oulu, Finland \\ Email: harri.oinas-kukkonen@oulu.fi \\ ${ }^{4}$ Department of Psychology, Health \& Technology, University of Twente, the \\ Netherlands \\ Email:j.vangemert.pijnen@utwente.nl
}

\section{Abstract}

This article introduces the theme issue on social interaction and reflection for behaviour change. A large body of research exists on systems designed to help users in changing their behaviours, for instance, to exercise more regularly or to reduce energy consumption. Increasingly, these systems focus on multiple users, often to encourage open-ended reflection rather than prescribing a particular course of action. As background for this theme issue, this article presents a literature review on behaviour change support systems that focus on social interaction and reflection. The review highlights five key approaches amongst these systems: social traces, social support, collective use, reflection-in-action, and reflection-on-action. Each approach offers unique benefits but also challenges for the design of behaviour change support systems. We highlight how the articles in this theme issue contribute to our current understanding of these five approaches, and beyond that, set out some broad directions for future work.

Keywords: Persuasive technology; behaviour change; behaviour change support systems; social interaction; social traces; social support; collective use; reflection; reflection-in-action; reflection-on-action.

\section{Introduction}

Personal and ubiquitous computing systems of many types, from smartphone apps and wearable devices to sensors and displays embedded in our environment, are focussed on helping users to achieve their goals in changing their behaviours. Many systems focus on health, e.g., to help people engage in regular physical activity $[1,2]$, follow a healthy diet $[3,4]$ or a therapy reducing depression [5], or give up unhealthy habits like smoking cigarettes [6,7]. In the area of sustainability, systems have focussed on helping households and 
workplaces reduce their consumption of electricity [8,9] and water [10,11], encourage reduction of waste and recycling [12,13], and use of alternative modes of transportation [14]. More recently, systems have turned to more mundane activities like household chores [15] and prolonged TV consumption [16], as well as digital behaviours like managing digital distractions and interruptions $[17,18]$.

Much of the work in this area has been inspired by BJ Fogg's book on persuasive technology [19]. Drawing from theories in social psychology, Fogg lays out different techniques with which computers can change human attitudes and behaviours. More than one hundred papers on behaviour change in the $\mathrm{CHI}$ conference proceedings over a period of 10 years [20], and a yearly conference dedicated to persuasive technology, highlight the impact of this area of inquiry for human-computer interaction (HCI).

More recently, Oinas-Kukkonen has proposed the concept of behaviour change support systems [21]. The concept of behaviour change support systems builds on the traditional notion of persuasive technology [19], but it places more emphasis on people's needs and goals [21]. In particular, the concept acknowledges that people's goals vary from forming a new behaviour to maintaining habits, and that therefore behaviour change support systems need to be designed accordingly to assist users in pursuing their goals [21]. This subtle shift in focus from what the technology can offer towards supporting people's needs and goals has helped to address some of the critiques of persuasive technology as traditionally conceived, such as their top-down design [22], their prescriptive approach in what behaviours are desirable [23], and their lack of sensitivity for the varying needs of individual users [24].

This theme issue extends this line of research with a focus on systems that incorporate (1) social interaction and (2) reflection as means to support behaviour change. Firstly, research on persuasive technology and behaviour change support systems has traditionally focussed on individual users. However, the widespread use of smartphones and social media has created new opportunities to connect people and to exchange support. For instance, peer groups can be an important source of social support throughout the change process [25], and personal and ubiquitous computing technologies can help them collaborate through tracking and sharing of behavioural data [26]. Secondly, while many technologies for behaviour change prescribe goals and nudge people towards particular choices, personal and ubiquitous computing technologies offer opportunities for more open-ended reflection on personal behaviour. For example, the Quantified Self movement highlights the popularity of self-tracking through smartphone apps and sensor technologies to better understand and reflect on one's actions [27]. Beyond that, ambient displays like the Power-Aware Cord [28], which glows in response to energy consumption, facilitate reflection by bringing unconscious aspects of our lifestyles such as our electricity consumption to our awareness, thereby making them available for conscious deliberation.

Rather than merely summarising the articles in this theme issue, we wish to introduce this theme issue by discussing five broad themes in designing for social interaction and reflection: social traces, social support, collective use, reflection-in-action, and reflection-on-action. These themes emerged in our analysis of the articles assembled in this theme issue and related 
research. They provide a deeper grounding to these articles and highlight connections between them. Furthermore, they offer an indication of our own research on behaviour change support systems and where we see potential for further research. These themes are not meant to be mutually exclusive, nor are they meant to be comprehensive or complete reviews of related work. Instead, we hope to show why the area covered in this theme issue is important, where research on behaviour change support systems has come from, and where it may be headed.

\section{Social Interaction}

There is ample evidence of the strong influence exerted by social interaction on people's behaviours. From classic experiments of conformity [29] to more recent studies of large-scale social networks [30] to the social and humanized web [31] we see how our interactions with the people around us influence our activities, both online and offline. The following section presents an overview of how behaviour change support systems mediate social interaction, ranging from minimal social traces of other people's activities to rich interactions via social media to systems that focus on the collective rather than the individual.

\section{Social Traces}

A first approach for behaviour change support systems is to provide social traces, where users encounter traces or patterns of other users. These may be anonymous, such as usage statistics or averages of previous users' data entries, or the traces may be created by known others, such as knowledgeable hobbyists or celebrities. They open the possibility for users to be supported through the presence of others, without necessarily requiring expressions of identity, explicit relationships or rich interactions.

Social traces are in widespread use and bring a range of recognised benefits. Firstly, social traces can provide an awareness of the issues concerned with behaviour change as well as the impact of collective behaviour change. For example, Kim and Paulos [32] sought to raise awareness about poor indoor air quality, which is difficult to detect for humans through sight and smell alone. They deployed a system that measured indoor air quality and shared the information between households of friends, which promoted awareness and discussion amongst the household members. Reitberger et al. [33], on the other hand, explored how visualising the impact of collective behaviour may motivate an individual to change their habits. Their aim was to encourage the use of public transport and bicycles rather than cars, in order to reduce pollution and road congestion. While an individual may have little impact on the levels of pollution and traffic congestion in a city, they showed that detecting and visualizing the impact of collective behaviour through anonymized traces would motivate an individual.

Secondly, in addition to anonymous traces there is need for trailblazers in the social web [31] who for various reasons seek to be thought leaders and who have followers in their endeavour. Such an activity fulfils people's need especially because even though people can 
be interested in many diverse topics, they most often just want to follow what others recommend them rather than wanting to personally spend time to do research about them. Typically, any user may create these trails and share them with others, but the difference to anonymous traces is that trailblazers purposefully polish their ideas to match with the interests of tracers. This social behaviour can be seen especially with social networking systems such as Twitter.

Thirdly, social traces are in widespread use to indicate norms. Social and cultural norms are expectations for appropriate behaviour within a social setting [34]. Sometimes norms are made explicit through signs (like 'no smoking' signs), at other times we implicitly adjust our behaviour based on our observations of what those around us are already doing. Behaviour change support systems can use social traces to convey norms about information that is not easily observable. For example, the lambent shopping trolley handle [35] helps shoppers choose sustainable products in the supermarket. The handle provides factual information about food miles (the distance the product has travelled from the time of its production until it reaches the consumer). Furthermore, it shows social traces of other shoppers, where shoppers can compare their chosen product to the average shopper's food miles. A similar approach has been used in various studies of domestic energy monitoring systems, where users received information about the energy consumption of their own household as well as the households of their friends [36] and neighbours [37].

Fourth, social traces can be used to encourage comparison and competition. For example, the Houston system designed by Consolvo and colleagues [38] encouraged people to incorporate more walking into their daily routine. The system quantified the user's walking time to encourage personal goal setting, and this information was also shared with other users of the application to facilitate comparison and competition between users. Admittedly, studies of behaviour change support systems using goal-setting and competition have found mixed results. Some users find motivation through competition, which helps them to start changing behaviours and to stay committed [38,39], whereas some users find that overly competitive interaction goes against the spirit of positively encouraging behaviour change [40,39]. More clarification on this is warranted.

In summary, social traces can provide useful support for behaviour change through enhanced awareness of the issues concerned with behaviour change, trailblazing effect, information about norms and motivation through competition. However, offering traces that are meaningful and support change, without encouraging competitiveness that adversely affects change, remains an ongoing challenge for the design of behaviour change support systems.

\section{Social Support}

The second approach is concerned with rich interactions that offer social support. Social support refers to various forms of exchange between people to enhance their wellbeing. It can involve esteem support, intimacy, companionship and validation. Furthermore, social support 
can involve both tangible support and material aid as well as informational support like advice and help in problem solving [41-43].

Research on online support has typically focused on exchanges within anonymous online communities. For example, a longitudinal study of such a community by Maloney-Krichmar and Preece [44] reported a positive influence of online support on participants' health and wellbeing. Burke and colleagues [45] found that rhetoric matters in online communities, and particularly that explicit requests increase the likelihood of getting a supportive reply. Wang and colleagues [46] showed that exposure to emotional support (but not informational support) increased the member's commitment to the online community.

Social network sites like Facebook hold further potential for the exchange of social support because most users log on daily to interact with other users [47]. Hence, they offer a useful infrastructure to connect individuals with peers with similar behaviour change concerns. For example, a recent study of a Facebook page for smoking cessation shows how users at different stages of change offer advice and seek emotional support in this online setting [25]. A similar study of Twitter users shows how people exchange support online during their quit attempt and even when they relapse [48].

Furthermore, social network sites facilitate interactions with their offline social networks, like family members, friends and colleagues. Some of these contacts have a good knowledge of a person's needs and emotional state and so provide tailored support [49,50]. Several studies have deployed applications building on Facebook to utilize the support available from personal contacts. For example, the BinCam system developed by Comber and Thieme [12] used Facebook to facilitate discussion and support between friends in shared households to reduce waste and encourage recycling. Munson et al. [51] built a wellness application for Facebook that encouraged users to share personal experiences with good things that happened to them.

A residual challenge in designing for social support is to find a balance between encouraging expressions of support and allowing a user to remain private. The research discussed thus far has shown that individuals benefit from the social support available through social network site and online communities. However, there are several reasons why individuals are typically reluctant to ask for support or share their personal experiences online. In general, acknowledging the differences between problem domains, people who are trying to change are often ambivalent about seeking support due to concerns about obstructive responses [42], potential pressure from peers [51] as well as concerns about failure to change and embarrassment [52,53]. It is not surprising, then, that expressions of support in anonymous online communities [54] as well as social network sites [25] typically come from people who have successfully changed rather than those who are trying to change. Furthermore, the presence of existing social networks on Facebook can also adversely complicate social support. In everyday life people disclose personal matters selectively to obtain support, keeping them private from other people. Therefore, the social network site Google+ facilitates selective sharing of personal information. Google+ users typically segment their online personal networks according to life facets, relationship strength, or shared interests [55]. 
Despite the availability of similar features to segment personal networks on Facebook, information is typically broadcast to all of these social contexts from close friends to distant acquaintances, which creates tensions in the way people would like to present themselves to others. Hence, while some people desire support from close ties on Facebook, they typically prefer to disclose challenges about their behaviour change and wellbeing to anonymous online communities [49].

\section{Designing for Collective Use}

A third approach towards behaviour change is concerned with designing for the collective. So far, this article has largely focussed on systems that facilitate social interaction between individuals. Social traces rely on input from a larger group, but they primarily benefit the individual who can compare herself with others. Similarly, social support is generated by a group of users, but persuasive applications, discussion forums and social network sites alike typically offer accounts for individual users, who benefit from the resources provided by peers and personal networks. Having said that, some of the work discussed so far has shown a partially collective orientation. Several systems focussed on behaviour change in a household [36,12], yet each of these systems was delivered to individuals, either through personal smartphone apps or Facebook accounts. The persuasive game "Smoke?" [56] was based on collectivist values like harmony and group opinion, but likewise it was designed for individual play.

In contrast to this, a growing body of research has started to design systems for collectives of users, like local communities and groups of co-workers. Katzeff and colleagues [8], for example, sought to encourage reflection and discussion on electricity amongst co-workers in factory and office settings. Rather than focussing on single workers, they designed ambient light installations and deployed them in spaces where workers met and socialised. Hence, the displays provided the workers with an opportunity to collectively reflect on activities that consume electricity. The design of Twinkly Lights [57] also focussed on workplaces. Instead of encouraging reflection, however, the Twinkly Lights installation used a series of ambient lights embedded into the floor to entice employees and visitors into taking the stairs rather than the elevator. In a similar way, the Piano Staircase system used a playful approach to encourage commuters at an underground railway station to take the stairs instead of the escalator. As the name suggests, the stairs looked like piano keys and it sounded like piano keys being played when walked on [58].

The work by Valkanova and colleagues focused on behaviour change within a local community [59]. They designed the Reveal-it! System, which visualised individual, average neighbourhood and average city-wide energy consumption on a semi-public space to encourage discussion about electricity consumption [59]. In a similar way, the Tidy Street Project used large scale visualisations to engage an entire street into discussions about electricity [60]. In contrast to the Reveal-it! system, however, the Tidy Street project focussed on the average consumption of households in the street, rather than a particular individual's 
household. This was to foster collaboration rather than competitiveness between different households.

All these systems embedded technologies into the social settings that groups of people inhabited, like people's homes, shared workspaces and open public spaces. As with any ubiquitous technology, they raise questions about the appropriate level of engagement for a setting, e.g., whether people notice the system but also whether they want to be exposed to persuasive information or even share their own data in a public display. Unlike with personal systems, people inhabiting a space embedded with technology may have less choice to avoid the space and thereby opt out of becoming a user. On the other hand, the examples discussed here have shown the potential of well-designed systems to engage groups in discussion and actual behaviour change. Some of the examples, like the Tidy Street Project [60] and the ambient light installations by Katzeff and colleagues [8] focussed on encouraging reflection in groups. The following section will further expand on behaviour change support systems designed for reflection, both individually as well as collectively.

\section{Reflection}

Ideally, reflecting about certain aspects of one's life provides valuable insights, which in turn lead individuals to reconsider and possibly change particular attitudes or behaviours. This idea of reflection can be traced back to ancient Greece, where "gnōthi seauton" (know thyself) was one of the Delphic maxims. In HCI, the notion of reflection has been emphasized by the slow technology agenda [61], which underlines the creation of technology for reflection over a mere focus on speed and efficiency. More recently, a slowness lens has been used by Siegel and Beck to conceptualise "slow change" interaction design focusing on behavioural change in the long term with a holistic approach [62]. Similarly, in this theme issue on behaviour change support systems we are interested in going beyond quick persuasion following prescribed goals, towards technologies that enable people to engage with particular facets of their lives, which potentially also result in a change in behaviour.

Many systems for reflection use ambiguous, abstract and ambient visualizations to involve people in an open-ended sense making process. For example, Long and Vines [63] present an interactive artwork for ambiguous reflection, which senses contextual and user data and presents it in a way that leaves room for the interpretation on behalf of the users. The role of their interactive artwork is confined to aggregation and artful representation of the data rather than definite sense making and display of decisive output. Similarly, the design of Twinkly Lights [57], which nudged people towards taking the stairs instead of the elevator, used ambient interfaces that were unobtrusive and provided ambiguous feedback on the amount of elevator and stair use in the building. Despite their unobtrusive nature, these examples show that ambiguous approaches still influence behaviour.

To unpack this complex notion of reflection and its different forms, Fleck and Fitzpatrick [64] frame a design landscape for reflection and propose five different levels of reflection: revisiting, revisiting with explanation, exploring relationships, fundamental change and wider 
implications. Their fourth level, fundamental change, which they also denote as transformative reflection, is the most relevant to the notion of reflection for behaviour change, which is highlighted in this theme issue. This kind of reflection might foster a change in understanding or practice based on the acquisition of a different point of view and the opening of new perspectives.

Another way to distinguish different forms of reflection is based on their temporal relation to the activity at hand and was proposed by Schön [65]. In his work about reflective practice, Schön differentiates between reflection-in-action and reflection-on-action, where the first denotes contemplation at the time of doing ("thinking on our feet"), whereas the latter is about deliberately pausing to think about previous activities. In the following sections we will use these two types of reflection as a lens to understand behaviour change support systems and the opportunities for ubiquitous computing to support these two modes of reflection.

\section{Reflection-in-Action}

Due to their situated, distributed and connected nature, ubiquitous computing systems have the potential to foster reflection-in-action. Sensors worn on the body and embedded into the environment can be used to track relevant information about the context of a user [66], which then can be processed and presented to the user via and mobile and ambient displays [67] to provide feedback while a person goes through an activity. For example, commercially available devices such as Fitbit One [68] and the Nike+ Fuelband [69] track physical movement and provide real-time feedback through a wearable device while a person is walking, running, cycling, etc.

Using personal and ubiquitous computing systems technologies for self-tracking has become increasingly popular with the rise of the Quantified Self movement [70], which aims to facilitate self-knowledge through obtaining quantifiable measurements about people. Recent statistics [71] show that in stark contrast to its beginning in an IT-affine subculture, selftracking has become a mainstream phenomenon: $69 \%$ of U.S. adults track a health indicator for themselves or a loved one, and $60 \%$ track their weight, diet or exercise routing. Those who track, often do this informally, either on paper (34\% of self-trackers) or in their heads (49\%). Nevertheless, $21 \%$ of them use technology, i.e. a spreadsheet, website, app, or device to log their data [71]. Recent qualitative studies have started to explore how people incorporate tracking into their everyday lives, i.e., how it helps them to reflect on their current situation and in the pursuit of their goals [72], as well as how it enables them to maintain changes in the long-term [26].

Studies of self-tracking technologies such as Ubifit Garden [73] show the capacity of such technology to affect and change people's behaviour. Ubifit Garden enabled reflection-inaction by employing a glanceable garden metaphor implemented on user's mobile phones that enabled them to easily assess the state of their tracked physical activity levels with a quick look on their phones. In a similar vein, the perCues application for sustainable mobility [33] was designed to use a mobile device to provide cues to influence users decisions towards 
abstaining from using their cars and taking public transportation instead. These cues were to be presented in the right moment in order to utilize the principle of Kairos [19], which states that a persuasive intervention has a higher possibility of success if the timing is right. The findings of an exploratory study with a mobile perCues paratype [33] supported the idea of finding opportune moments, but it also raised other challenges for supporting reflection-inaction, i.e., how to provide feedback that builds on the users' knowledge-in-action and supports their actions without interrupting them.

\section{Reflection-on-Action}

Reflection-on-action facilitated by personal and ubiquitous computing systems does not take place immediately during a particular activity but rather after the activity has ended. Similarly to reflection-in-action, sensors can be utilized to capture action related user and contextual information in an unobtrusive manner, but the feedback is given to the users at a different point in time, typically in situations where they have more time and resources available to engage with this information. Therefore systems that support reflection-on-action can allow for more extensive interaction and even experimentation with one's data. These systems can go beyond the mere representation of sensor information by e.g. showing connections, correlations and (long term) patterns in the collected data.

Fish'n'steps [40] is an example for a system that is built to support reflection-on-action. It utilizes pedometers for step tracking and visualizes a user's progress with a fish bowl metaphor on a PC screen in a post-hoc manner. Similarly, commercial systems such as Fitbit provide a web-based dashboard that gives a multi-faceted view on one's data on activities, calories burned, sleep, etc. in addition to the step data that is available on the wearable Fitbit device. Furthermore, the management of chronic conditions such as diabetes, that already require logging of certain parameters can be augmented with technology. Smith et al. [74] used self-tracking for young people with diabetes to encourage reflection-on-action to improve understanding and communication regarding the self-management of the disease. Other systems in that area like the mySugr Companion app [75] allow for playful reflection about one's success with the management of diabetes via the use of persuasive strategies such as goal-setting and rewards.

An ongoing challenge for reflection-on-action is how to best represent data for a particular activity. One aspect of this challenge is the degree of ambiguity in the data. Ambiguous information as in the interactive artwork discussed by Long and Vines can encourage deep engagement to make sense of the feedback. Concrete numerical information as in the Fitbit system, on the other hand, leaves less room for interpretation but still allows for reflection about a particular activity. Dourish and Mazmanian [76] highlight that different ways of representing numerical data allow for different degrees of knowing and reflection, e.g., lists support ordering of information, trees show hierarchies and tables show relations between different data points. Fan et al. [77] explore alternatives to highly ambiguous and numerical information, creating visualisations that increase enjoyment in addition to numerical and graph-based visualizations. Correspondingly, Froehlich et al. [10] studied a range of 
visualizations for feedback about water consumption to promote sustainable behaviour. The results showed that the same designs were perceived in very different ways by users, evoking positive feelings like accountability and playfulness as well negative reactions such as perceptions of intrusiveness and guilt. An explanation for this difference is that these visualizations did not merely show consumption patterns but rather revealed household activities and routines. Understanding these social dynamics is important for the acceptance of such systems in the home. Specifically, users preferred information with a high level of data granularity, but they also wanted to be able to choose between different data representations, i.e. different periods of time and different units of measurement (amounts, costs). These findings indicate that designers need to carefully consider their choices in what data gets collected and how it gets represented, also taking into account the social practices surrounding these data, as they impact how users make sense of the world and their activities.

\section{Contributions in this Theme Issue}

This theme issue assembles five papers. One of the papers offers conceptual-theoretical contributions to current understanding of social interaction and reflection in behaviour change. Wiafe et al. [78] build on Festinger's theory of cognitive dissonance [79] and the Persuasive Systems Design model [80] to propose a method of characterising users in the context of their behaviour change. The article introduces the 3D-RAB model, which highlights eight different states of cognitive dissonance. These states clarify which type(s) of change in the cognitive state of users the system is attempting to support. It also provides guidance for researchers and designers of behaviour change support systems in selecting suitable techniques to achieve positive change.

Oduor et al. [81] offer a more technical contribution through persuasive software design patterns for social influence, which developers of behaviour change support systems can use to guide their implementations. Bringing together software design pattern thinking and theory on social influence, the article offers four patterns: social learning and facilitation, competition, cooperation and recognition. The patterns for social learning and competition are based on sharing traces, whereas cooperation and recognition rely on rich exchanges of support between users. These persuasive software design patterns aid reflection on persuasive software design and development, and they may also aid in designing for collectives.

The remaining three papers offer contributions based on research-through-design. Zuckerman and Gal-Oz [82] developed a mobile phone application "StepByStep" to explore the effectiveness of different (social) traces to promote physical activity. They found that a basic self-tracking approach significantly increased the participants' daily walking time over a 2week period. They further added personal rewards to gamify self-tracking as well as social traces to compare and compete with other users. However, when compared with the basic self-tracking system, all systems yielded similar amounts of walking time. These findings show that the main benefit of the StepByStep system was not through the social traces it 
offered, but through the self-tracking data that provided real-time feedback of performance towards a goal and opportunities for reflection-in-action.

Reitberger et al. [83] designed Nutriflect to raise awareness and enable reflection on nutrition. Nutriflect consisted of a shared display situated in people's homes as well as mobile application that provided in-situ information on products and personal nutrition while shopping for groceries. A field study showed that the two systems complemented each other: the home display served as an ambient display that heightened awareness and encouraged interaction and reflection-on-action amongst the household members. The mobile system, on the other hand, was used for focussed interaction with personalised and product-specific information on nutrition to support reflection-in-action while shopping for groceries.

The final article by Parker [84] focused on designing behaviour change support systems for collectives, i.e., a local neighbourhood. Parker developed Community Mosaic, a system that encourages local residents to share the steps they are taking to eat healthfully. The system asked users to share photos and stories about their behaviour not for personal benefit but for the benefit of others in their community. A field study showed that the system encouraged community members to reflect upon and analyse their personal habits as well as to take active steps to eat more healthfully. Creating photos and stories for the benefit of other community members also led to benefits for the individual users. The participants reflected more deeply on their eating habits, because they were not only concerned about their own health but also about how their stories would be perceived by other members of their local community.

\section{Conclusions}

In this article we have presented a review of the current state of research on systems that use social interaction and reflection as means to support behaviour change. We have highlighted five key approaches in this area: social traces, social support, collective use, reflection-inaction, and reflection-on-action. Each approach offers unique benefits but also challenges to designers and researchers of behaviour change support systems:

1. Social traces support awareness-building, trailblazing, normative influence, and motivation through collaboration and competition. However, a key challenge is how to present traces that are minimal yet provide meaningful support. A second key challenge is how to support interaction through numerical traces without encouraging competiveness that may undermine people's desire to change.

2. Social support refers to various forms of exchange between people to help them change their behaviours, like esteem support, companionship, tangible support, advice and help. Online communities and social network sites facilitate the exchange of support online, but encouraging contributions from users as well as how to best support users in managing their privacy throughout the behaviour change process remain ongoing challenges.

3. Systems designed for collectives are typically embedded into the settings that they inhabit, like people's homes, shared workspaces and open public spaces. These 
systems can encourage change on a large scale, but designing situated technologies is challenging in terms of finding an appropriate level of engagement for a given setting as well as in supporting the privacy of individuals who access and inhabit them.

4. Reflection-in-action is supported by systems that provide feedback at the time of action. These systems can be effective as they offer resources for reflection at the right time. However, providing feedback that builds on and supports knowledge-inaction for a given activity without interrupting it remains a challenge.

5. Reflection-on-action is encouraged by systems where resources for reflection are offered after the activity has ended. A key challenge in this area is how to best represent data for a particular activity, i.e., what data to gets chosen, the extent of concreteness (or ambiguity) in its representation, and how different sources of data are structured and related to one another.

We have highlighted how the articles that follow in this theme issue contribute to our current understanding of designing for social interaction and reflection to support behaviour change. These articles address the challenges described above, but clearly challenges like encouraging engagement, mutual support and meaning-making as well as protecting people's privacy require larger efforts. More work is also needed to understand the usefulness and effectiveness of the various approaches in different contexts of behaviour change, how to incorporate knowledge on behaviour change from other disciplines like public health and psychology, how to best utilise emerging personal and ubiquitous computing systems, and how to work with people to create new systems that support them in their behaviour change processes. It is our hope that by looking back and taking stock of more than ten years of research, we have also set out some broad trajectories for future work on designing technologies that assist and empower people in reaching their chosen goals.

\section{Acknowledgements}

This theme issue is the outcome of the First International Workshop on Behavior Change Support Systems (BCSS) held at the Eighth International Conference on Persuasive Technology held in Sydney, Australia in April 2013. The editors would like to thank their coconvener Sitwat Langrial and the participants of this workshop for their assistance with this theme issue. We would like to thank our supportive expert reviewers: Nilufar Baghaei, Annemarie Braakman, Shanton Chang, Rik Crutzen, Brian Cugelman, Sebastian Deterding, Marc Fabri, Eva Ganglbauer, Florian Güldenpfennig, Giulio Jacucci, Pasi Karppinen, Saskia Kelders, Rilla Khaled, Olga Kulyk, Tuck Leong, Geke Ludden, Marianna Obrist, Hans Ossebaard, Wally Smith, Terje Solvoll, Wolfgang Spreicer, Agnis Stibe, Kristian Torning, Roos van der Vaart, Greg Wadley, and Jobke Wentzel.

This research was supported by the Cancer Council Victoria and the Australian Research Council (ARC), grant LP110100046. This research was part of the OASIS research group of Martti Ahtisaari Institute, University of Oulu. This study was supported by the SalWe 
Research Program for Mind and Body (Tekes - The Finnish Funding Agency for Technology and Innovation grant 1104/10).

\section{References}

1. Berkovsky S, Freyne J, Coombe M (2012) Physical activity motivating games: be active and get your own reward. ACM Transactions on Computer-Human Interaction (TOCHI) 19 (4):1-41. doi:10.1145/2395131.2395139

2. Rodríguez M, Roa J, Morán A, Nava-Muñoz S (2012) CAMMInA: a mobile ambient information system to motivate elders to exercise. Pers Ubiquit Comput 17 (6):1127-1134. doi:10.1007/s00779012-0561-y

3. Linehan C, Leeman T, Borrowdale C, Lawson S (2013) Crowd saucing: social technology for encouraging healthier eating. interactions 20 (1):53-57. doi:10.1145/2405716.2405729

4. Orji R, Vassileva J, Mandryk R (2013) LunchTime: a slow-casual game for long-term dietary behavior change. Pers Ubiquit Comput 17 (6):1211-1221. doi:10.1007/s00779-012-0590-6

5. Van Gemert-Pijnen EJ, Kelders MS, Bohlmeijer TE (2014) Understanding the usage of content in a mental health intervention for depression: an analysis of log data. J Med Internet Res 16 (1):e27. doi:10.2196/jmir.2991

6. Khaled R, Fischer R, Noble J, Biddle R (2008) A qualitative study of culture and persuasion in a smoking cessation game. In: Proceedings of PERSUASIVE 2008. Springer, Berlin, pp 233-245. doi:10.1007/978-3-540-68504-3_20

7. Ploderer B, Smith W, Pearce J, Borland R (2014) A mobile app offering distractions and tips to cope with cigarette craving: a qualitative study. JMIR mHealth uHealth 2 (2):e23. doi:10.2196/mhealth.3209

8. Katzeff C, Broms L, Jönsson L, Westholm U, Räsänen M (2013) Exploring sustainable practices in workplace settings through visualizing electricity consumption. ACM Transactions on ComputerHuman Interaction (TOCHI) 20 (5):1-22. doi:10.1145/2501526

9. Pierce J, Paulos E (2012) Beyond energy monitors: interaction, energy, and emerging energy systems. In: Proceedings of CHI 2012. ACM, New York, pp 665-674. doi:10.1145/2207676.2207771

10. Froehlich J, Findlater L, Ostergren M, Ramanathan S, Peterson J, Wragg I, Larson E, Fu F, Bai M, Patel S, Landay JA (2012) The design and evaluation of prototype eco-feedback displays for fixturelevel water usage data. In: Proceedings of CHI 2012. ACM, New York, pp 2367-2376. doi:10.1145/2207676.2208397

11. Pearce J, Smith W, Nansen B, Murphy J (2009) SmartGardenWatering: experiences of using a garden watering simulation. In: Proceedings of OZCHI 2009. ACM, New York, pp 217-224. doi: $10.1145 / 1738826.1738861$

12. Comber R, Thieme A (2013) Designing beyond habit: opening space for improved recycling and food waste behaviors through processes of persuasion, social influence and aversive affect. Pers Ubiquit Comput 17 (6):1197-1210. doi:10.1007/s00779-012-0587-1

13. Ganglbauer E, Fitzpatrick G, Comber R (2013) Negotiating food waste: Using a practice lens to inform design. ACM Transactions on Computer-Human Interaction (TOCHI) 20 (2):1-25. doi: $10.1145 / 2463579.2463582$

14. Froehlich J, Dillahunt T, Klasnja P, Mankoff J, Consolvo S, Harrison B, Landay JA (2009) UbiGreen: investigating a mobile tool for tracking and supporting green transportation habits. In: Proceedings of CHI 2009. ACM, New York, pp 1043-1052. doi:10.1145/1518701.1518861 
15. Reitberger W, Kastenmiller M, Fitzpatrick G (2013) Invisible work: an ambient system for awareness and reflection of household tasks. In: Berkovsky S, Freyne J (eds) Persuasive Technology, vol 7822. Lecture Notes in Computer Science. Springer Berlin Heidelberg, pp 180-191. doi:10.1007/978-3-642-37157-8_22

16. Reitberger W, Güldenpfennig F, Fitzpatrick G (2012) Persuasive technology considered harmful? an exploration of design concerns through the TV companion. In: Bang M, Ragnemalm E (eds) Persuasive Technology. Design for Health and Safety, vol 7284. Lecture Notes in Computer Science. Springer Berlin Heidelberg, pp 239-250. doi:10.1007/978-3-642-31037-9_21

17. Bickmore T, Mauer D, Crespo F, Brown T (2007) Persuasion, task interruption and health regimen adherence. In: Kort Y, Ijsselsteijn W, Midden C, Eggen B, Fogg BJ (eds) Persuasive Technology, vol 4744. Lecture Notes in Computer Science. Springer Berlin Heidelberg, pp 1-11. doi:10.1007/978-3540-77006-0_1

18. Dabbish L, Kraut RE (2004) Controlling interruptions: awareness displays and social motivation for coordination. In: Proceedings of CSCW 2004. ACM, New York, pp 182-191. doi:10.1145/1031607.1031638

19. Fogg B (2002) Persuasive technology: Using computers to change what we think and do. Morgan Kaufmann, San Francisco, CA.

20. Hekler EB, Klasnja P, Froehlich JE, Buman MP (2013) Mind the Theoretical Gap: Interpreting, Using, and Developing Behavioral Theory in HCI Research. In: Proceedings of CHI 2013. ACM, New York. doi:10.1145/2470654.2466452

21. Oinas-Kukkonen H (2013) A foundation for the study of behavior change support systems. Pers Ubiquit Comput 17 (6):1223-1235. doi:10.1007/s00779-012-0591-5

22. Brynjarsdottir H, Hakansson M, Pierce J, Baumer E, DiSalvo C, Sengers P (2012) Sustainably unpersuaded: how persuasion narrows our vision of sustainability. In: Proceedings of the 2012 ACM annual conference on Human Factors in Computing Systems. ACM, Austin, Texas, USA, pp 947-956. doi:10.1145/2207676.2208539

23. Baumer EPS, Katz SJ, Freeman JE, Adams P, Gonzales AL, Pollak J, Retelny D, Niederdeppe J, Olson CM, Gay GK (2012) Prescriptive persuasion and open-ended social awareness: expanding the design space of mobile health. In: Proceedings of CSCW 2012. ACM, New York, pp 475-484. doi:10.1145/2145204.2145279

24. He HA, Greenberg S, Huang EM (2010) One size does not fit all: Applying the transtheoretical model to energy feedback technology design. In: Proceedings of CHI 2010. ACM, New York, pp 927936. doi:10.1145/1753326.1753464

25. Ploderer B, Smith W, Howard S, Pearce J, Borland R (2012) Patterns of support in an online community for smoking cessation. In: Proceedings of C\&T 2013. ACM, New York, pp 1511-1514. doi:10.1145/2207676.2208613

26. Fritz T, Huang EM, Murphy GC, Zimmermann T (2014) Persuasive technology in the real world: a study of long-term use of activity sensing devices for fitness. In: Proceedings of CHI 2014. ACM, New York, pp 487-496. doi:10.1145/2556288.2557383

27. Choe EK, Lee NB, Lee B, Pratt W, Kientz JA (2014) Understanding quantified-selfers' practices in collecting and exploring personal data. In: Proceedings of CHI 2014. ACM, New York, pp 1143-1152. doi: $10.1145 / 2556288.2557372$

28. Gustafsson A, Gyllenswärd M (2005) The power-aware cord: energy awareness through ambient information display. In: Extended Abstracts of CHI 2005. ACM, New York, pp 1423-1426. doi:10.1145/1056808.1056932 
29. Asch SE (1955) Studies of independence and conformity: A minority of one against a unanimous majority. Psychological Monographs 70:1-70

30. Christakis NA, Fowler JH (2009) Connected: the surprising power of our social networks and how they shape our lives. Little, Brown and Co., New York.

31. Oinas-Kukkonen H, Oinas-Kukkonen H (2013) Humanizing the web: change and social innovation. Palgrave Macmillan, Basingstoke, UK.

32. Kim S, Paulos E (2010) InAir: sharing indoor air quality measurements and visualizations. In: Proceedings of CHI. ACM, New York, pp 1861-1870. doi:10.1145/1753326.1753605

33. Reitberger W, Ploderer B, Obermair C, Tscheligi M (2007) The perCues framework and its application for sustainable mobility. In: Proceedings of PERSUASIVE 2007, vol 4744. Springer, Berlin, pp 92-95. doi:10.1007/978-3-540-77006-0_11

34. Dolan P, Britain G (2010) MINDSPACE: Influencing behaviour through public policy. Cabinet Office.

35. Kalnikaitè V, Bird J, Rogers Y (2013) Decision-making in the aisles: informing, overwhelming or nudging supermarket shoppers? Pers Ubiquit Comput 17 (6):1247-1259. doi:10.1007/s00779-0120589-z

36. Kjeldskov J, Skov MB, Paay J, Pathmanathan R (2012) Using mobile phones to support sustainability: a field study of residential electricity consumption. In: Proceedings of CHI 2012. ACM, New York, pp 2347-2356. doi:10.1145/2208276.2208395

37. Erickson T, Li M, Kim Y, Deshpande A, Sahu S, Chao T, Sukaviriya P, Naphade M (2013) The Dubuque electricity portal: evaluation of a city-scale residential electricity consumption feedback system. In: Proceedings of CHI 2013. ACM, New York, pp 1203-1212. doi:10.1145/2470654.2466155

38. Consolvo S, Everitt K, Smith I, Landay JA (2006) Design requirements for technologies that encourage physical activity. In: Proceedings of CHI 2006. ACM, New York, pp 457-466. doi:10.1145/1124772.1124840

39. Eiriksdottir E, Kestranek D, Catrambone R, Mynatt ED, Miller AD, Xu Y, Poole ES (2012) This is not a one-horse race: understanding player types in multiplayer pervasive health games for youth. In: Proceedings of CSCW 2012. ACM, New York, pp 843-852. doi:10.1145/2145204.2145330

40. Lin J, Mamykina L, Lindtner S, Delajoux G, Strub H (2006) Fish'n'Steps: encouraging physical activity with an interactive computer game. In: Proceedings of UbiComp 2006. Springer, Berlin, pp 261-278. doi:10.1007/11853565_16

41. Khaled R, Barr P, Noble J, Biddle R (2006) Investigating social software as persuasive technology. In: Proceedings of PERSUASIVE 2006. Springer, Berlin, pp 104-107. doi:10.1007/11755494_15

42. Maitland J, Chalmers M (2011) Designing for peer involvement in weight management. In: Proceedings of CHI 2011. ACM, New York, pp 315-324. doi:10.1145/1978942.1978988

43. Wills TA (1991) Social support and interpersonal relationships. Review of Personality and Social Psychology 12:265-289

44. Maloney-Krichmar D, Preece J (2005) A multilevel analysis of sociability, usability, and community dynamics in an online health community. ACM Transactions on Computer-Human Interaction (TOCHI) 12 (2):201-232. doi:10.1145/1067860.1067864

45. Burke M, Joyce E, Kim T, Anand V, Kraut R (2007) Introductions and requests: rhetorical strategies that elicit response in online communities. In: Steinfield C, Pentland BT, Ackerman M, Contractor N (eds) Proceedings of C\&T 2007. Springer, London, pp 21-39. doi:10.1007/978-1-84628905-7_2 
46. Wang Y-C, Kraut R, Levine JM (2012) To stay or leave? The relationship of emotional and informational support to commitment in online health support groups. In: Proceedings of CSCW 2012. ACM, New York, pp 833-842. doi:10.1145/2145204.2145329

47. Facebook (2014) Key facts. http://newsroom.fb.com/Key-Facts. Accessed 1 March 2014

48. Murnane EL, Counts S (2014) Unraveling abstinence and relapse: smoking cessation reflected in social media. In: Proceedings of CHI 2014. ACM, New York, pp 1345-1354.

doi:10.1145/2556288.2557145

49. Newman MW, Lauterbach D, Munson SA, Resnick P, Morris ME (2011) It's not that I don't have problems, I'm just not putting them on Facebook: Challenges and opportunities in using online social networks for health. In: Proceedings of CSCW 2011. ACM, New York, pp 341-350. doi:10.1145/1958824.1958876

50. Olsen E, Kraft P (2009) ePsychology: A pilot study on how to enhance social support and adherence in digital interventions by characteristics from social networking sites. In: Proceedings of PERSUASIVE 2009. ACM, Claremont, California, pp 1-6. doi:10.1145/1541948.1541991

51. Munson S, Lauterbach D, Newman M, Resnick P (2010) Happier together: integrating a wellness application into a social network site. In: Proceedings of PERSUASIVE 2010. Lecture Notes in Computer Science. Springer, Berlin, pp 27-39. doi:10.1007/978-3-642-13226-1_5

52. Ploderer B, Smith W, Howard S, Pearce J, Borland R (2012) Introducing the ambivalent socialiser. In: Proceedings of CHI 2012. ACM, New York, pp 1511-1514. doi:10.1145/2207676.2208613

53. Purpura S, Schwanda V, Williams K, Stubler W, Sengers P (2011) Fit4life: The design of a persuasive technology promoting healthy behavior and ideal weight. In: Proceedings of CHI 2011. ACM, New York, pp 423-432. doi:10.1145/1978942.1979003

54. Cobb NK, Graham AL, Abrams DB (2010) Social network structure of a large online community for smoking cessation. Am J Public Health 100 (7):1282-1289. doi:10.2105/AJPH.2009.165449

55. Kairam S, Brzozowski M, Huffaker D, Chi EH (2012) Talking in circles: Selective sharing in Google+. In: Proceedings of CHI 2012. ACM Press, New York, pp 1065-1074

56. Khaled R, Barr P, Biddle R, Fischer R, Noble J (2009) Game design strategies for collectivist persuasion. In: Proceedings of SIGGRAPH 2009. ACM, New York, pp 31-38. doi:10.1145/1581073.1581078

57. Rogers Y, Hazlewood WR, Marshall P, Dalton N, Hertrich S (2010) Ambient influence: can twinkly lights lure and abstract representations trigger behavioral change? In: Proceedings of UbiComp 2010. ACM, New York, pp 261-270. doi:10.1145/1864349.1864372

58. The Fun Theory. http://www.thefuntheory.com/. Accessed 14 January 2014

59. Valkanova N, Jorda S, Tomitsch M, Moere AV (2013) Reveal-it!: the impact of a social visualization projection on public awareness and discourse. In: Proceedings of CHI 2013. ACM, New York, pp 3461-3470. doi:10.1145/2470654.2466476

60. Bird J, Rogers Y (2010) The pulse of tidy street: measuring and publicly displaying domestic electricity consumption. In: Workshop on Energy Awareness and Conservation through Pervasive Applications (Pervasive 2010).

61. Hallnäs L, Redström J (2001) Slow technology - designing for reflection. Pers Ubiquit Comput 5 (3):201-212. doi:10.1007/PL00000019

62. Siegel MA, Beck J (2014) Slow change interaction design. Interactions 21 (1):28-35. doi:10.1145/2542649 
63. Long K, Vines J (2013) Mind pool: encouraging self-reflection through ambiguous bio-feedback. In: Extended Abstracts of CHI 2013. ACM, New York, pp 2975-2978. doi:10.1145/2468356.2479588

64. Fleck R, Fitzpatrick G (2010) Reflecting on reflection: framing a design landscape. In: Proceedings of OZCHI 2010. ACM, New York, pp 216-223. doi:10.1145/1952222.1952269

65. Schön DA (1983) The reflective practitioner: how professionals think in action. Basic Books, New York.

66. Dey AK (2001) Understanding and Using Context. Pers Ubiquit Comput 5 (1):4-7. doi:10.1007/s007790170019

67. Schmidt A, Häkkilä J, Atterer R, Rukzio E, Holleis P (2006) Utilizing mobile phones as ambient information displays. In: Extended Abstracts of CHI 2006. ACM, New York, pp 1295-1300. doi:10.1145/1125451.1125692

68. Fitbit. http://www.fitbit.com/. Accessed 7 March 2014

69. Nike + Fuelband SE. http://www.nike.com/us/en_us/c/nikeplus-fuelband. Accessed 11 March 2014

70. Quantified Self Labs (2014) Quantified Self: self knowledge through numbers. http://quantifiedself.com/. Accessed 10 March 2014

71. Fox S, Duggan M (2013) Tracking for Health Pew Internet and American Life Project, Washington, DC

72. Rooksby J, Rost M, Morrison A, Chalmers MC (2014) Personal tracking as lived informatics. Proceedings of CHI 2014:1163-1172. doi:10.1145/2556288.2557039

73. Consolvo S, McDonald DW, Toscos T, Chen MY, Froehlich J, Harrison B, Klasnja P, LaMarca A, LeGrand L, Libby R, Smith I, Landay JA (2008) Activity sensing in the wild: a field trial of ubifit garden. In: Proceedings of CHI 2008. ACM, New York, pp 1797-1806. doi:10.1145/1357054.1357335

74. Smith BK, Frost J, Albayrak M, Sudhakar R (2007) Integrating glucometers and digital photography as experience capture tools to enhance patient understanding and communication of diabetes self-management practices. Pers Ubiquit Comput 11 (4):273-286. doi:10.1007/s00779-0060087-2

75. mySugr Companion. http://mysugr.com/companion/. Accessed 7 March 2014

76. Dourish P, Mazmanian M (2011) Media as Material: Information Representations as Material Foundations for Organizational Practice. In: Proceedings of the Third International Symposium on Process Organization Studies. Corfu, Greece,

77. Fan C, Forlizzi J, Dey AK (2012) A spark of activity: exploring informative art as visualization for physical activity. In: Proceedings of UbiComp 2012. ACM, New York, pp 81-84. doi: $10.1145 / 2370216.2370229$

78. Wiafe I, Nakata K, Gulliver S (this issue) Categorizing users in behavior change support systems based on cognitive dissonance. Pers Ubiquit Comput

79. Festinger L (1957) A theory of cognitive dissonance. Stanford University Press, Stanford, CA.

80. Oinas-Kukkonen H, Harjumaa M (2009) Persuasive systems design: Key issues, process model, and system features. Communications of the Association for Information Systems 24 (1):485-500

81. Oduor M, Alahäivälä T, Oinas-Kukkonen H (this issue) Persuasive software design patterns for social influence. Pers Ubiquit Comput 
82. Zuckerman O, Gal-Oz A (this issue) Deconstructing gamification: evaluating the effectiveness of continuous measurement, virtual rewards and social comparison for promoting physical activity. Pers Ubiquit Comput

83. Reitberger W, Spreicer W, Fitzpatrick G (this issue) Situated and mobile displays for reflection on shopping and nutritional choices. Pers Ubiquit Comput Springer

84. Parker AG (this issue) Reflection-through-performance: personal implications of documenting health behaviors for the collective. Pers Ubiquit Comput Springer 


\section{University Library}

\section{- M M N E R VA A gateway to Melbourne's research publications}

Minerva Access is the Institutional Repository of The University of Melbourne

Author/s:

Ploderer, B;Reitberger, W;Oinas-Kukkonen, H;van Gemert-Pijnen, J

Title:

Social interaction and reflection for behaviour change

Date:

2014-10-01

Citation:

Ploderer, B., Reitberger, W., Oinas-Kukkonen, H. \& van Gemert-Pijnen, J. (2014).

Social interaction and reflection for behaviour change. PERSONAL AND UBIQUITOUS COMPUTING, 18 (7), pp.1667-1676. https://doi.org/10.1007/s00779-014-0779-y.

Persistent Link:

http://hdl.handle.net/11343/282702 